\title{
Molecular definition of severe acute respiratory syndrome coronavirus 2 receptor-binding domain mutations: Receptor affinity versus neutralization of receptor interaction
}

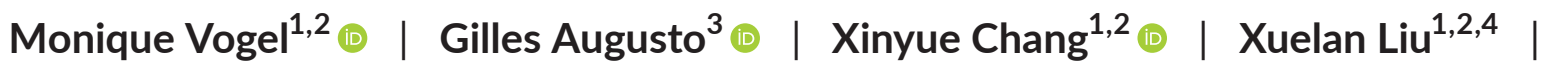 \\ Daniel Speiser $^{1,2}$ | Mona O. Mohsen ${ }^{1,2}$ | Martin F. Bachmann ${ }^{1,2,3,4}$
}

${ }^{1}$ Department of Immunology, Inselspital, University clinic of Rheumatology and Immunology, Bern, Switzerland

${ }^{2}$ Department of BioMedical Research, University of Bern, Bern, Switzerland

${ }^{3}$ The Jenner Institute, Nuffield Department of Medicine, Centre for Cellular and Molecular Physiology (CCMP), University of Oxford, Oxford, UK

${ }^{4}$ Dermatology, International Immunology Centre, Anhui Agricultural University, Hefei, China

Correspondence

Martin F. Bachmann, Department of Immunology, University Clinic of Rheumatology and Immunology, University Hospital Bern, Salihaus 2, CH3010 Bern, Switzerland.

Email: martin.bachmann@dbmr.unibe.ch

Funding information

We thank Saiba AG, the Swiss National Science Foundation (SNF grant 31003A_185114) and the International Immunology Centre, Anhui Agricultural University, Hefei, China for financial support

\begin{abstract}
Background: Several new variants of SARS-CoV-2 have emerged since fall 2020 which have multiple mutations in the receptor-binding domain (RBD) of the spike protein. It is unclear which mutations affect receptor affinity versus immune recognition.

Methods: We produced wild type RBD, RBD with single mutations (E484K, K417N, or N501Y) or with all three mutations combined and tested their binding to ACE2 by biolayer interferometry (BLI). The ability of convalescent sera to recognize RBDs and block their interaction with ACE2 was tested as well.

Results: We demonstrated that single mutation N501Y increased binding affinity to ACE2 but did not strongly affect its recognition by convalescent sera. In contrast, single mutation E484K had almost no impact on the binding kinetics, but essentially abolished recognition of RBD by convalescent sera. Interestingly, combining mutations E484K, K417N, and N501Y resulted in a RBD with both features: enhanced receptor binding and abolished immune recognition.

Conclusions: Our data demonstrate that single mutations either affect receptor affinity or immune recognition while triple mutant RBDs combine both features.

KEYWORDS

ACE2, affinity, neutralization, RBD, SARS-CoV-2
\end{abstract}

\section{1 | INTRODUCTION}

Severe acute respiratory syndrome coronavirus 2 (SARS-CoV-2) has caused a pandemic that is characterized in many countries by several waves of infection. ${ }^{1,2}$ While the origin of these infection waves may differ in different regions of the world, the latest increase seen in numbers of infected individual is apparently caused by the occurrence of mutated viral strains. ${ }^{3}$ Recent advances in genome sequencing have allowed to establish nucleotide databases of SARS-CoV-2 genome in real time (https://www.ncbi.nlm.nih. gov/sars-cov-2) and to identify mutations of the different SARSCoV-2 isolates. ${ }^{4}$ The most prominent mutated strains are the following variants: B.1.1.7. (UK variant), P.1 (Japan/Brazil variant), and B.1.351 (South Africa variant) and the newly emerging India variant,

Monique Vogel and Gilles Augusto equally contributed to this work.

This is an open access article under the terms of the Creative Commons Attribution-NonCommercial-NoDerivs License, which permits use and distribution in any medium, provided the original work is properly cited, the use is non-commercial and no modifications or adaptations are made.

(c) 2021 The Authors. Allergy published by European Academy of Allergy and Clinical Immunology and John Wiley \& Sons Ltd. 


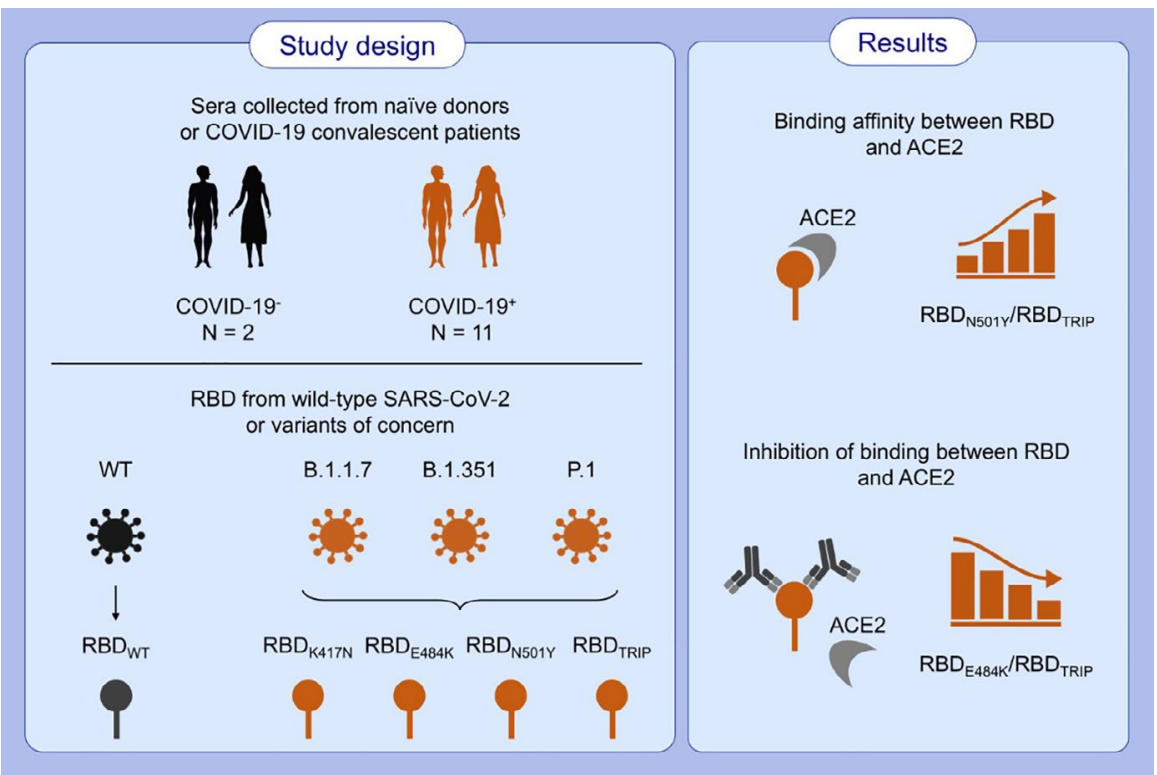

\section{GRAPHICAL ABSTRACT}

In this study, we tested RBD of the spike protein with single mutations or with all three mutations combinations for binding to sera from naïve donors and convalescent COVID-19 patients. Convalescent sera recognize RBD of the early SARS-CoV-2 emerged from Wuhan, China. Single mutations (E484K or N501Y) either affect receptor affinity to ACE2 or immune recognition of RBD by convalescent sera. Combining three-point mutations (K417N, E484K, and N501Y) in RBD increased binding to ACE2 and abolished recognition of RBD by sera of convalescent patients.

Abbreviations: ACE2, angiotensin-converting enzyme 2; B.1.1.7., SARS-CoV-2 UK variant; B.1.351, SARS-CoV-2 South Africa variant; B.1.6.1.7, SARS-CoV-2 India variant; P.1, SARS-CoV-2 Japan/Brazil variant; COVID-19, coronavirus disease 2019; RBD, receptor-binding

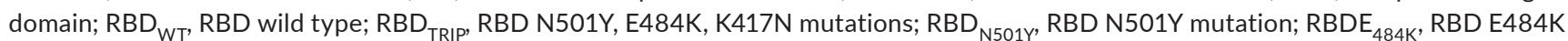
mutation; $\mathrm{RBD}_{\mathrm{K} 417 \mathrm{~N}}$, RBD K417N mutation; SARS-CoV-2, severe acute respiratory syndrome coronavirus 2; and WT, wild type.

B.1.6.1.7, ${ }^{5,6}$ which show mutations in the receptor-binding domain (RBD) and receptor-binding motif (RBM) of the spike (S) glycoprotein (Table 1, Figure 1). RBD and in particular RBM are responsible for interaction with the cellular receptor ACE2 and are the primary target of neutralizing antibodies ${ }^{7}$ (Figure 1). Mutations altering the RBD conformation have been shown to permit SARS-CoV-2 to escape antibody neutralization and for the rapid infectivity and transmission of SARS-CoV-2. ${ }^{8}$ Mutant viruses may spread more efficiently because they show increased affinity for the receptor or because they escape neutralizing antibody responses. ${ }^{9}$ The importance of receptor affinity has been illustrated by SARS-CoV-1, which showed a fourfold lower affinity for ACE2 compared to SARS-CoV-2 and also was much less contagious and showed strongly reduced transmission than SARS-CoV-2. ${ }^{10}$

Viruses that escape neutralization are typically called serotypes and usually may only occur when a large proportion of individuals show antibody-based immunity against the original strain and further spread may only be possible by escape of neutralizing antibody responses. ${ }^{11}$ For SARS-CoV-2, it remains to be shown definitively whether or not some variants are new serotypes; however, on a global scale, the number of the mutations present in the main variants and their infection rates in certain regions of the world with high previous infection rates are compatible with serotype formation.
Here we assessed the molecular basis for antibody escape and how the RBD mutations present in two variants of concern (B.1.1.7 and P.1) influence the affinity to the receptor.

\section{2 | MATERIAL AND METHODS}

\section{1 | Protein expression and purification}

The SARS-CoV-2 receptor-binding domain of the wild-type RBD $\left(R D_{W T}\right)$, the single $R B D$ mutants $\left(R D_{K 417 N}, R_{E D} D_{E 484 K}\right.$, and $R_{B} D_{\text {N501Y }}$ ), and the triple RBD mutant $\left(R_{B D} D_{T R I P}\right)$ were expressed using Expi293F cells (Invitrogen, ThermoFisher Scientific). The genes

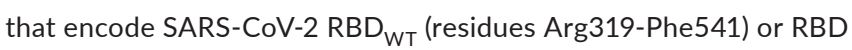
mutants with a C-terminal 6-His-tag were inserted into pTwist CMV BetaGlobin WPRE Neo vector (Twist Bioscience). The construct plasmids were transfected into Expi293F cells using ExpiFectatmine 293 transfection kit (Gibco, ThermoFisher Scientific). The supernatant of cell culture containing the secreted RBDs was purified using His-Trap HP column (GE Healthcare). Collected $\mathrm{RBD}_{\mathrm{WT}}$ or RBD mutated proteins were equilibrated in PBS and kept at $-20^{\circ} \mathrm{C}$. ACE2-mFc was purchased from Sino Biological. Biotinylated and non-biotinylated soluble human ACE2 fused to mouse IgG2a Fc proteins were kindly provided by PD Dr. Alexander Eggel (University 
Clinic of Rheumatology and Immunology, Inselspital) who received the plasmid from Prof. Peter Kim (Stanford University).

\section{2 | Human sera}

Human sera were obtained from 11 COVID-19 convalescent patients which were recruited at the University Hospital of Bern, Bern, Switzerland as described. ${ }^{12}$ Participants were recruited via three different routes: (a) inpatients with a SARS-CoV-2 test result (real-time PCR; RT-PCR), (b) medical personnel of the Inselspital, and (c) residual material from patients stored at the Liquid Biobank Bern (www. biobankbern.ch). Inclusion criteria of inpatients are (a) hospitalization in Inselspital, (b) tested positive for SARS-CoV-2 using RT-PCR (nasopharyngeal swab), (c) aged 18 or older, and (d) signed general consent.

\section{3 | ELISA assay}

Corning half area 96-well plates were coated with $1 \mu \mathrm{g} / \mathrm{ml} \mathrm{RBD}_{\mathrm{WT}}$ or mutated RBDs in PBS overnight at $4^{\circ} \mathrm{C}$ and then blocked with PBS/0.15\% casein. Convalescent human sera were added, serially diluted 1:3, and incubated on plates for $1 \mathrm{~h}$ at room temperature. Bound IgG antibodies were detected with goat anti-human IgG-POX antibody (Nordic MUbio). ELISA was developed with tetramethylbenzidine (TMB), stopped by adding equal $1 \mathrm{M} \mathrm{H}_{2} \mathrm{SO}_{4}$ solution, and read at $\mathrm{OD}_{450 \mathrm{~nm}}$. Results are shown as endpoint titers (EPT) which were calculated as the maximum dilution factors for which $450-\mathrm{nm}$ absorbance was no less than $0.15 \mathrm{AU}$, the background baseline.

\section{4 | RBDwt and RBDmut kinetics by bio-layer interferometry}

The analysis of binding kinetics of $R B D_{W T}$ and $R B D_{T R I P}$ to ACE2$\mathrm{mFc}$ was performed by BioLayer Interferometry (BLI) using an Octet RED96e (Fortebio) instrument. High precision Streptavidin (SAX, ForteBio) biosensors were saturated with $7.5 \mu \mathrm{g} / \mathrm{ml}$ biotinylated ACE2-mFc in BLI assay buffer (PBS, 0.1\% BSA, 0.02\% Tween 20) for $10 \mathrm{~min} . \mathrm{RBD}_{\mathrm{WT}}$ and $\mathrm{RBD}_{\mathrm{TRIP}}$ were prepared as twofold serial dilution (typically 50, 25, 12.5, 6.25, and $3.125 \mathrm{nM}$ ) in BLI assay buffer plus buffer blanks. Kinetic values were calculated by ForteBio data analysis software using a 1:1 binding model.

\section{5 | Bio-layer interferometry -based competitive assay}

The ability of the sera of the COVID convalescent patient to compete with ACE2 for binding to $\mathrm{RBD}_{\mathrm{WT}}$ and $\mathrm{RBD}_{\mathrm{TRIP}}$ was tested in a sandwich format assay on the Octet RED96e (Fortebio). Anti-penta-His (HIS1K) biosensors were loaded for 10 min with $\mathrm{RBD}_{\mathrm{WT}}$ and $\mathrm{RBD}_{\mathrm{TRIP}}$ at a concentration of $7.5 \mu \mathrm{g} / \mathrm{ml}$ in BLI assay buffer followed by addition of samples (diluted 1:20 in BLI assay buffer) from convalescent human sera. To assess whether the sera can inhibit the binding of ACE2 to RBD ${ }_{W T}$ and $\mathrm{RBD}_{\mathrm{TRIP}}$, ACE2-mFc $(50 \mathrm{nM})$ was added to biosensor. For control two additional sensors with $B L I$ buffer were used, one for baseline and one without serum sample to determine binding of ACE2-mFc alone. The results are expressed of single individual. The response data were normalized using ForteBio data analysis software version1.2.0.1.55.

\section{6 | Data and statistical analysis}

All statistical tests were performed using GraphPad PRISM 8.0 (GraphPad Software, Inc.). ELISA data in graphs are displayed as endpoint titers measured at a cutoff 0.15 OD $450 \mathrm{~nm}$. Comparison between $\mathrm{RBD}_{\mathrm{WT}}$ and mutated RBDs were analyzed by two-way ANOVA test for ELISA and paired two-tailed Student's t-test for BLI assay. $\alpha=0.05$ and statistical significance are displayed as $p \leq .05\left(^{*}\right)$, $p \leq .01\left(^{* *}\right), p \leq .005\left(^{* * *}\right)$, and $p \leq .001\left(^{* * * *}\right)$.

\section{3 | RESULTS}

\section{1 | Structural model and binding kinetics of SARS-CoV-2 RBD variants to ACE2}

To address the questions of antibody binding strength and competition mechanistically, we have expressed the RBD of the early SARSCoV-2 that emerged in Wuhan, China $\left(R B D_{W T}\right)$ which serves as positive control. In parallel, we have produced RBD of the isolate P.1

TABLE 1 Characteristics of the main SARS-CoV-2 mutants

\begin{tabular}{|c|c|c|c|}
\hline \multirow[b]{2}{*}{ Name } & \multicolumn{2}{|l|}{ Origin } & \multirow[b]{2}{*}{ Spike mutations $^{a}$} \\
\hline & Location & Date & \\
\hline B.1.1.7 & United Kingdom (UK) & February 2020 & $\begin{array}{l}7 \text { mutations: N501Y, A570D, D614G, P681H, T716I, S982A, D1118H } \\
2 \text { deletions: H69-V70del, Y144del }\end{array}$ \\
\hline B.1.351 & South Africa & October 2020 & $\begin{array}{l}9 \text { mutations: L18F, D80A, D215G, R246I, K417N, E484K, N501Y, D614G, A701V } \\
1 \text { deletion: LAL 242-244 del }\end{array}$ \\
\hline P.1 & Japan/Brazil & January 2021 & $\begin{array}{l}12 \text { mutations: L18F, T20N, P26S, D138Y, R190S, K417T, E484K, N501Y, D614G, } \\
\text { H655Y, T1027I, V1176F }\end{array}$ \\
\hline B.1.6.1.7 & India & January 2021 & 6 mutations: D111D, G412D, L452R, E484Q, D614G, H655Y, P681R \\
\hline
\end{tabular}

${ }^{\mathrm{a}}$ In bold the mutations in the receptor-binding domain (RBD). 


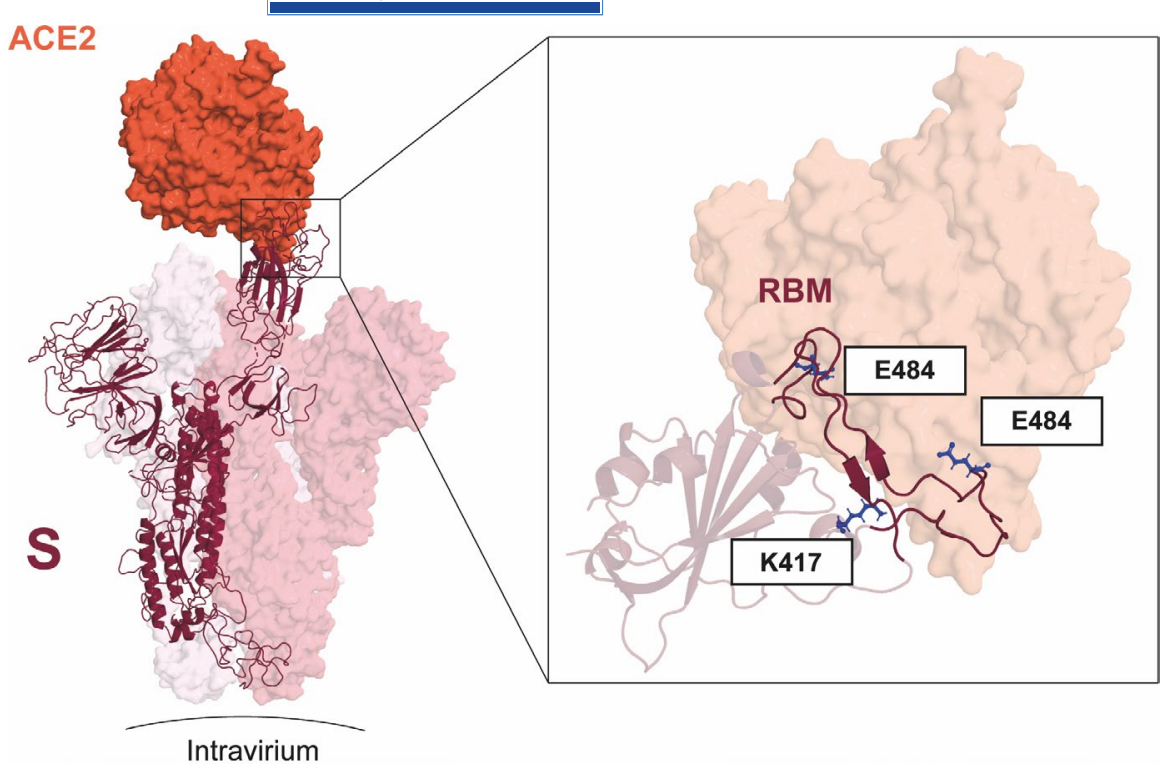

FIGURE 1 Key mutations of variants B.1.351 and P1 fall on the interface between the RBD and ACE2. (left) $S$ monomer (purple ribbon) bound to ACE2 ectodomain (orange surface). In detail, the positions of residues K417, E484, and N501 (blue sticks) are highlighted. Mutations E484K and N501K occur on the RBM segments (dark purple ribbon), while K417N occurs on helix $\alpha 4$ of RBD. From PDB files 6ACG and 6MOJ
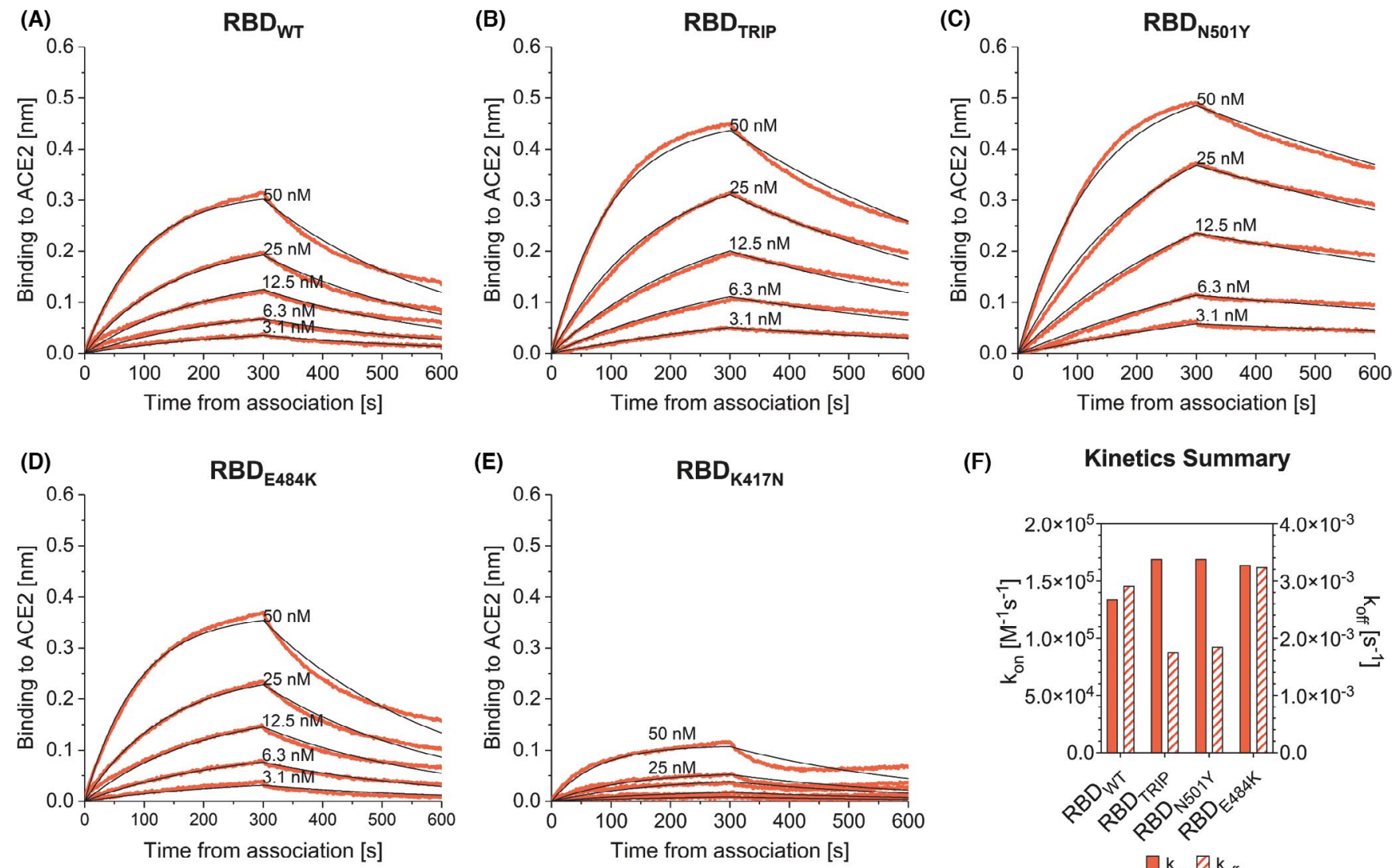

(F)

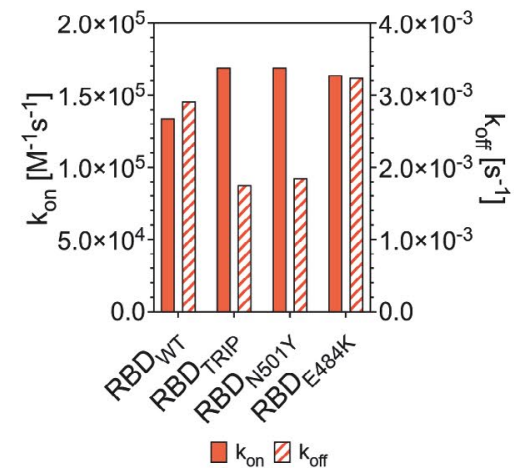

FIGURE 2 Binding kinetics of $\operatorname{RBD}_{\mathrm{WT}}(\mathrm{A}), \mathrm{RBD}_{\mathrm{TRIP}}(\mathrm{B}), \mathrm{RBD}_{\mathrm{N501Y}}(\mathrm{C}), \mathrm{RBD}_{\mathrm{E} 484 \mathrm{~K}}(\mathrm{D})$, and $\mathrm{RBD}_{\mathrm{K} 417 \mathrm{~N}}(\mathrm{E})$ to hACE2. In all assays, both association and dissociation were performed in $300 \mathrm{~s}$. The resulting $\mathrm{k}_{\text {on }}$ and $\mathrm{k}_{\text {off }}$ values from each condition are compared in panel (F)

exhibiting RBD with three-point mutations $\left(\mathrm{RBD}_{\mathrm{TRIP}}\right)$ namely $\mathrm{K} 417 \mathrm{~N}$, a lysine $(\mathrm{K})$ to asparagine $(\mathrm{N})$ at position 417 , E484K, a glutamate $(\mathrm{E})$ to lysine at position 484 and N501Y, an asparagine $(\mathrm{N})$ to tyrosine $(\mathrm{Y})$ at position 501, two of which are located in the RBM (E484K, N501Y; shown in Figure 1A). ${ }^{13}$ In order to assess the role of each of these mutations on the binding of the RBD to ACE2, we generated single RBD mutants each containing one of the above mentioned mutations $\left(\mathrm{RBD}_{\mathrm{K} 417 \mathrm{~N}}, \mathrm{RBD}_{\mathrm{E} 484 \mathrm{~K}}\right.$, and $\left.\mathrm{RBD}_{\mathrm{N} 501 \mathrm{Y}}\right)$. All RBDs were purified to homogeneity, and the affinity to recombinant ACE2 was determined by Biolayer Interferometry using Octet technology. ${ }^{14}$ The BLI assays showed that the affinity of ACE2 for RBD $\mathrm{R}_{\text {TRIP }}$ (shown in Figure $2 \mathrm{~B}, \mathrm{~F}$, Table 2, $\mathrm{K}_{\mathrm{D}} \approx 10 \mathrm{nM}$ ) was about twice as high as for 
$\mathrm{RBD}_{\mathrm{WT}}$ (shown in Figure 2A,F, Table 2, $\mathrm{K}_{\mathrm{D}}=20.5 \mathrm{nM}$ ). The affinity of the SARS-CoV-2 for ACE2 has been reported to be only fourfold higher compared to SARS-CoV-1; thus, a difference of two reported here between $R B D_{W T}$ and $R B D_{\text {Trip }}$ is expected to be biologically significant and most likely reflects enhanced infectivity. In contrast, the introduction of a single E484K mutation in the RBD $\left(R^{2} D_{E 484 K}\right)$ did not affect receptor affinity (shown in Figure 2D,F). For comparison, the affinity observed for $\mathrm{RBD}_{\mathrm{N} 501 \mathrm{Y}}$ was threefold lower $\left(\mathrm{K}_{\mathrm{D}} \approx 6 \mathrm{nM}\right.$, shown in Figure 2C,F, Table 2). Interestingly, K417N mutation in the single RBD mutant $\left(\mathrm{RBD}_{\mathrm{K} 417 \mathrm{~N}}\right)$ resulted in completely altered binding properties (shown in Figure $2 \mathrm{E}$ ). $\mathrm{RBD}_{\mathrm{K} 417 \mathrm{~N}}$ showed much lower association rates and plateau levels and a non-monovalent pattern of dissociation rates (shown in Figure 2E, Table $2 \mathrm{~K}_{\mathrm{D}}$ could not be determined in a meaningful way). Presence of aggregates was not responsible for this effect, as purification by size exclusion immediately before measurements did not alter the binding kinetics observed (data not shown). However, since $\mathrm{K} 417 \mathrm{~N}$ is not present in the RBM, we did not further investigate this effect.

TABLE 2 Kinetic parameters of $\mathrm{RBD}_{\mathrm{WT}}$ and mutated RBDs calculated by BLI

\begin{tabular}{lccc} 
Analyte & $\mathrm{K}_{\mathrm{D}}[\mathrm{M}]$ & $\mathrm{k}_{\text {on }}\left[\mathrm{M}^{-1} \mathrm{~s}^{-1}\right]$ & $\mathrm{k}_{\text {off }}\left[\mathrm{s}^{-1}\right]$ \\
\hline $\mathrm{RBD}_{\mathrm{WT}}$ & $20.5 \times 10^{-9}$ & $1.34 \times 10^{5}$ & $2.91 \times 10^{-3}$ \\
$\mathrm{RBD}_{\text {TRIP }}$ & $10.3 \times 10^{-9}$ & $1.69 \times 10^{5}$ & $1.75 \times 10^{-3}$ \\
$\mathrm{RBD}_{\mathrm{N} 501 \mathrm{Y}}$ & $6.2 \times 10^{-9}$ & $1.69 \times 10^{5}$ & $1.85 \times 10^{-3}$ \\
$\mathrm{RBD}_{\text {E484K }}$ & $19.7 \times 10^{-9}$ & $1.64 \times 10^{5}$ & $3.24 \times 10^{-3}$ \\
$\mathrm{RBD}_{\text {K417N }}$ & $\mathrm{ND}$ & $\mathrm{ND}$ & $\mathrm{ND}$ \\
\hline
\end{tabular}

Abbreviations: ND, not determined; $\mathrm{RBD}_{\mathrm{E} 484 \mathrm{~K}}$, Receptor-Binding Domain E484K mutation; RBD $_{\mathrm{K} 417 \mathrm{~N}}$, Receptor-Binding Domain K417N mutation; $\mathrm{RBD}_{\mathrm{N} 501 \mathrm{Y}}$, Receptor-Binding Domain N501Y mutation; $\mathrm{RBD}_{\mathrm{TRIP}}$, Receptor-Binding Domain N501Y, E484K, K417N mutations; $\mathrm{RBD}_{\mathrm{WT}}$, Receptor-Binding Domain wild type.

\section{2 | Reduced ability of convalescent sera to recognize RDB variants}

To determine whether $\mathrm{RBD}_{\mathrm{WT}}$-specific immune sera might have a reduced ability to bind to mutated RBDs we performed ELISA and Biolayer Interferometry using sera from convalescent patients (shown in Figure 3). As expected $\mathrm{RBD}_{\mathrm{WT}}$ was well recognized by convalescent sera in ELISA experiments. In contrast, $\mathrm{RBD}_{\mathrm{K} 417 \mathrm{~N}}$ and $\mathrm{RBD}_{\mathrm{N501Y}}$ were recognized in a slightly impaired fashion (shown in Figure $3 \mathrm{~A}$ ). In marked contrast, mutation at position 484 essentially abolished recognition of both $\mathrm{RBD}_{\mathrm{E} 84 \mathrm{~K}}$ and $\mathrm{RBD}_{\mathrm{TRIP}}$. Corresponding results were obtained using Biolayer Interferometry (shown in Figure 3B). RBD-specific neutralizing antibodies typically block interaction of RBD with the viral receptor ACE2. We therefore assessed whether reduced binding of convalescent sera to $\mathrm{RBD}_{\text {TRIP }}$ was paralleled by reduced ability of these antibodies to block binding of ACE2 to the triple mutant (shown in Figure 3C). These experiments demonstrate that human convalescent sera essentially failed to block binding of ACE2 to RBD ${ }_{\text {TRIP, }}$ explaining why SARSCoV-2-induced antibodies largely fail to neutralize the triple mutant variants.

\section{DISCUSSION}

The newly emerging mutant RBDs may affect the affinity for the viral receptor. In addition, such mutations at the virus-receptor interaction face may alter the ability of RBD-specific antibodies-induced by previous infection-to neutralize the mutant viruses. When we investigated whether distinct mutations may affect receptor affinity, we found that N501Y mutation enhanced affinity for the viral receptor ACE2 both as a single mutation and as a triple mutation, while E484K mutation alone did not affect the interaction with ACE2.
FIGURE 3 Sera of COVID-19 convalescent patients recognize less mutated RBD (RBD TRIP, $\mathrm{RBD}_{\mathrm{N} 501 \mathrm{Y}}$, $\mathrm{RBD}_{\mathrm{E} 484 \mathrm{~K}}$, and $\left.\mathrm{RBD}_{\mathrm{K} 417 \mathrm{~N}}\right)$. A) Binding of sera from 12 COVID-19 convalescent patients and one COVID negative individual to $\mathrm{RBD}_{\mathrm{WT}}$ and mutated RBDs was determined by ELISA. Endpoint titers (EPT; dilution factor) individuals are shown as dots. Direct binding of sera to $\mathrm{RBD}_{\mathrm{WT}}$ and mutated RBDs (B) and competitive inhibition of ACE2-mFc interaction to $\mathrm{RBD}_{\mathrm{WT}}$ and mutated RBD (C) were assessed by BLI. The same sera (dilution 1:20) for each individual were usual. $p \leq .05\left(^{*}\right), p \leq .01\left(^{* *}\right), p \leq .005\left(^{* * *}\right)$, and $p \leq .0011^{(* * * *)}$
(A)

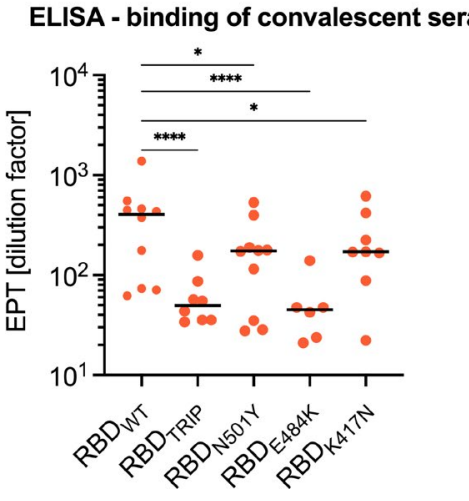

(B) BLI - binding of convalescent sera to $R^{R B D} D_{W T}$ and $R B D_{T R I P}$

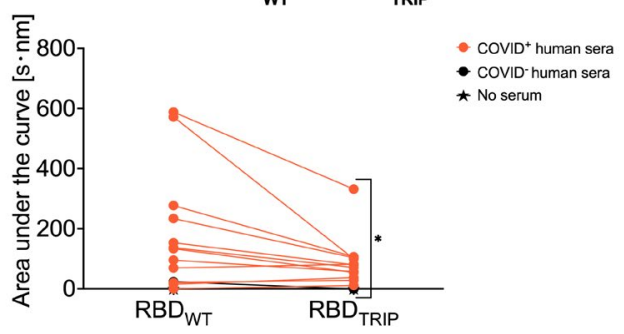

(C) BLI - inhibition of ACE2 binding to $R B D_{W T}$ and $R B D_{T R I P}$ by

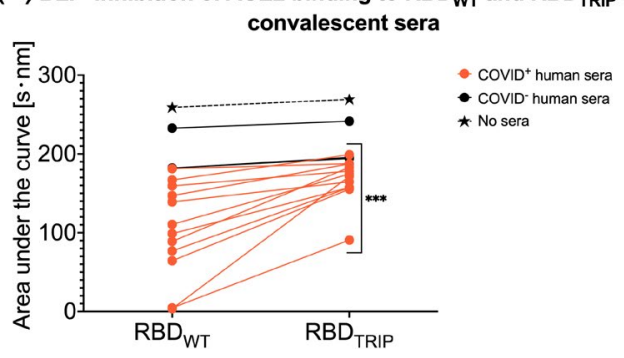


In addition, such mutations at the virus-receptor interaction interface may alter the ability of RBD-specific antibodies to recognize and neutralize the mutant variants. ${ }^{15} \mathrm{~A}$ previous study has shown that serum neutralization is not compromised by N501Y (also found in the strain B.1.1.7) ${ }^{16}$ In contrast, E484K (found B.1.1.7 and in P.1 strains) was associated with reduced neutralization by monoclonal antibodies and reduced recognition as shown here. ${ }^{17-19}$ Interestingly, studies applying in vitro pressure produced similar mutations as those that occurred naturally. ${ }^{20}$ In this study, we showed that convalescent sera have reduced ability to recognize $\mathrm{RDB}_{\text {TRIP }}$ variants explaining why the mutant SARS-CoV-2 strain P.1 is more infectious ${ }^{21}$ and less susceptible to neutralization by antibodies induced with $\mathrm{RBD}_{\mathrm{WT} \cdot{ }^{22}}$

In summary, our data demonstrate that distinct mutations may affect receptor affinity which likely affects viral infectivity versus recognition by convalescent sera which likely affects neutralization. These observations may shed light on the potential origin of the viral mutants. The variant with the mutation N501Y shows enhanced affinity but almost normal recognition by convalescent antibodies. This indicates that this variant spread largely by increased infectivity while recognition by antibodies of previously infected individuals was less relevant, a phenotype consistent with the epidemiology in the UK, where overall infection rates remain relatively low, rendering the previously infected individuals a relatively unimportant source of viral spread. ${ }^{23}$ In contrast, the triple mutant variant shows enhanced infectivity and escape from antibody recognition. It may therefore not be a coincidence that this variant originated in Manaus, a region in Brazil, previously seen to have seroprevalence of $>80 \%$, forcing the virus to escape immunity for further spreading. ${ }^{24}$

\section{ACKNOWLEDGEMENTS}

We thank Marianne Zwicker for production of wild-type and mutant RBDs. We thank PD Dr. Alexander Eggel and Dr. Daniel Brigger for providing biotinylated and non-biotinylated ACE2-mFc.

\section{CONFLICT OF INTEREST}

M. F. Bachmann is a board member of Saiba AG, involved in the development of RBD-CuMV, a vaccine against COVID-19. All other authors declare no conflict of interest.

\section{AUTHOR CONTRIBUTIONS}

M.V., G.A., and X.C. designed, performed, and interpreted most experiments. X.L. M.M. provided serum sample. M.V., G.A. and D.S. wrote the manuscript. MF.B. designed experiments and wrote the manuscript.

\section{ORCID}

Monique Vogel (D) https://orcid.org/0000-0002-5219-4033

Gilles Augusto (D) https://orcid.org/0000-0001-6509-0148

Xinyue Chang (D) https://orcid.org/0000-0001-7027-3889

\section{REFERENCES}

1. Choudhary S, Sreenivasulu K, Mitra P, Misra S, Sharma P. Role of genetic variants and gene expression in the susceptibility and severity of COVID-19. Ann Lab Med. 2021;41(2):129-138.

2. Bontempi E. The europe second wave of COVID-19 infection and the Italy "strange" situation. Environ Res. 2021;193:110476.

3. Bakhshandeh B, Sorboni SG, Javanmard AR, et al. Variants in ACE2; potential influences on virus infection and COVID-19 severity. Infect Genet Evol. 2021;90:104773.

4. Moustafa AM, Bianco C, Denu L, et al. Comparative analysis of emerging B.1.1.7+E484K SARS-CoV-2 isolates from Pennsylvania. bioRxiv. 2021. https://doi.org/10.1101/2021.04.21.440801

5. Gomez CE, Perdiguero B, Esteban M. Emerging SARS-CoV-2 variants and impact in global vaccination programs against SARSCoV-2/COVID-19. Vaccines 2021;9(3):243.

6. Zhao S, Lou J, Cao L, et al. Quantifying the transmission advantage associated with N501Y substitution of SARS-CoV-2 in the United Kingdom: an early data-driven analysis. J Travel Med. 2021;28(2):1-3.

7. Yi C, Sun $\mathrm{X}, \mathrm{Ye} J$, et al. Key residues of the receptor binding motif in the spike protein of SARS-CoV-2 that interact with ACE2 and neutralizing antibodies. Cell Mol Immunol. 2020;17(6):621-630.

8. Kim JS, Jang JH, Kim JM, Chung YS, Yoo CK, Han MG. Genomewide identification and characterization of point mutations in the SARS-CoV-2 genome. Osong Public Health Res Perspect. 2020;11(3):101-111.

9. Jacobson KB, Pinsky BA, Rath MEM, et al. Post-vaccination SARS-CoV-2 infections and incidence of the B.1.427/B.1.429 variant among healthcare personnel at a northern California academic medical center. medRxiv. 2021(Apr 24). https://doi. org/10.1101/2021.04.14.21255431

10. Huang $\mathrm{Y}$, Yang $\mathrm{C}, \mathrm{Xu} \mathrm{XF}, \mathrm{Xu} \mathrm{W}$, Liu SW. Structural and functional properties of SARS-CoV-2 spike protein: potential antivirus drug development for COVID-19. Acta Pharmacol Sin. 2020;41(9):1141-1149.

11. Bachmann MF, Zinkernagel RM. The influence of virus structure on antibody responses and virus serotype formation. Immunol Today. 1996;17(12):553-558.

12. Brigger D, Horn MP, Pennington LF, et al. Accuracy of serological testing for SARS-CoV-2 antibodies: first results of a large mixedmethod evaluation study. Allergy. 2021;76(3):853-865.

13. Faria NR, Mellan TA, Whittaker C, et al. Genomics and epidemiology of a novel SARS-CoV-2 lineage in Manaus, Brazil. Science. 2021;372(6544):815-821.

14. Petersen RL. Strategies using bio-layer interferometry biosensor technology for vaccine research and development. Biosensors. 2017;7(4):49.

15. Smaoui MR, Yahyaoui $H$. Unraveling the stability landscape of mutations in the SARS-CoV-2 receptor-binding domain. Sci Rep. 2021;11(1):9166

16. Xie X, Liu Y, Liu J, et al. Neutralization of SARS-CoV-2 spike 69/70 deletion, E484K and N501Y variants by BNT162b2 vaccine-elicited sera. Nat Med. 2021;27:620-621.

17. Wibmer CK, Ayres F, Hermanus T, et al. SARS-CoV-2 501Y.V2 escapes neutralization by South African COVID-19 donor plasma. Nat Med. 2021;27(4):622-625.

18. Greaney AJ, Starr TN, Gilchuk P, et al. Complete mapping of mutations to the SARS-CoV-2 spike receptor-binding domain that escape antibody recognition. Cell Host Microbe. 2021;29(1):44-57. e49.

19. Jangra $\mathrm{S}, \mathrm{Ye} \mathrm{C}$, Rathnasinghe $\mathrm{R}$, et al. The E484K mutation in the SARS-CoV-2 spike protein reduces but does not abolish neutralizing activity of human convalescent and post-vaccination sera. medRxiv. 2021(Jan 29). https://doi.org/10.1101/2021.01.26.21250543 
20. Andreano E, Piccini G, Licastro D, et al. SARS-CoV-2 escape in vitro from a highly neutralizing COVID-19 convalescent plasma. bioRxiv. 2020(Dec 28). https://doi.org/10.1101/2020.12.28.424451

21. Corum J, Zimmer C. Coronavirus variants and mutations. The New York Times. June 4, 2021.

22. Choudhary MC, Crain CR, Qiu X, Hanage W, Li JZ. SARS-CoV-2 sequence characteristics of COVID-19 persistence and reinfection. Clin Infect Dis. 2021(Apr 27). https://doi.org/10.1093/cid/ciab380

23. $\mathrm{BBC}$ news. Coronavirus infection levels continue to drop in the UK. March 5, 2021.

24. Candido DS, Claro IM, de Jesus JG, et al. Evolution and epidemic spread ofSARS-CoV-2 in Brazil.Science. 2020;369(6508):1255-1260.
How to cite this article: Vogel M, Augusto G, Chang X, et al. Molecular definition of severe acute respiratory syndrome coronavirus 2 receptor-binding domain mutations: Receptor affinity versus neutralization of receptor interaction. Allergy. 2022;77:143-149. https://doi.org/10.1111/all.15002 